\title{
Dental Caries Prevalence among 5-12 Year Old School Children in Urban and Rural Areas of Hyderabad District, Telangana, India
}

\author{
Dr. J. Sanjeev Naik ${ }^{1}$, Dr. Arshiya Sanobar ${ }^{2}$, Dr. P. Tarasingh ${ }^{3 *}$
}

\author{
${ }^{1}$ Associate Professor, Department of Dental Surgery, Gandhi Medical College \& Hospital, Gandhi Hospital, Musheerabad, Padmarao Nagar, \\ Secunderabad, Telangana 500003, India \\ ${ }^{2}$ Senior Resident, Department of Oral Surgery, Govt. Dental College \& Hospital, Afzalgunj Rd, near Police Station, Afzal Gunj, Hyderabad, Telangana \\ 500012, India \\ ${ }^{3}$ Associate Professor, Department of Pedodontics \& Preventive Dentistry, Govt. Dental College \& Hospital, Afzalgunj Rd, near Police Station, Afzal \\ Gunj, Hyderabad, Telangana 500012, India
}

DOI: $\underline{10.36347 / \text { sjds.2020.v07i09.007 }}$

| Received: 18.09.2020 | Accepted: 26.09.2020 | Published: 30.09.2020

*Corresponding author: Dr. P. Tarasingh

\section{Abstract}

\section{Original Research Article}

Dental caries is a multifactorial disease. The prevalence and incidence of it in a population is influenced by various risk factors such as age, sex, socioeconomic status, sugar exposures and oral hygiene habits. Hence, the present study was designed to assess the prevalence of dental caries in school going children in urban and rural areas of hyderabad district between 5 to 12 year age groups. Material \& Methods: A total of 1000 children aged 5-12 years were selected from 8 schools located in different geographic areas of hyderabad. Children were divided into two age groups, Group I - 5-8 years, Group II - 9-12 years. A trained dental surgeon using DMFT/deft index to diagnose dental caries performed the clinical examinations. Results: Among the two groups, Group I, showed high mean values (1.90) for dental caries in primary dentition and Group II, showed high mean values (1.48) in permanent dentition. In both the groups, decayed teeth accounted for the greatest percentage. Conclusion: The prevalence of dental caries was high in permanent dentition in group II and in group I, it was high in primary dentition. Rural areas of hyderabad district were affected more with caries compared to urban areas.

Keywords: Prevalence, Dental caries, School children, DEFT/deft Index.

Copyright @ 2020: This is an open-access article distributed under the terms of the Creative Commons Attribution license which permits unrestricted use, distribution, and reproduction in any medium for non-commercial use (NonCommercial, or CC-BY-NC) provided the original author and source are credited.

\section{INTRODUCTION}

Dental caries is the most common chronic infectious disease of oral hard tissues caused by plaque bacteria. It is five times more common than asthama and seven times more common than seasonal allergies. Dental caries affects both the sexes, all races, all socioeconomic status and all age groups. Dental caries will not only cause pain but also places a financial burden on the parent [1]. The prevention of dental caries has long been considered as an important task for the health profession. Several research activities are yet continuing to make the progress in diagnosing, treating and preventing dental caries.

Various studies exists on the prevalence of dental caries in the Indian population. In the year 1940, the prevalence of dental caries in 5 to 12 year old school children in India were $55.5 \%$ and it was increased to $68 \%$ in 1960 , later in subsequent years, it has reached to $89 \%[2,3]$. Also, in a survey of National oral health and fluoride mapping, it was found that prevalence of dental caries was about $50 \%$ in 5 year old children and close to $84 \%$ in older age population [4].

According to world health organization (WHO), the index age group of children $(5,12 \& 15$ years) presents a vulnerable population for the occurrence of dental caries. The age of 12 years has been considered as the global monitoring age for dental caries. Hence, the prevalence of dental caries among this age group needs to be assessed.

Dental caries is most commonly measured by the sum of decayed, missing and filled teeth (DMFT/deft index). This index is also widely used to assess the caries status at the population level for public health planning and policy-making purposes. DMFT/deft index is a cumulative caries measure, which indicates caries occurrence including past and present dental caries. Based on DMFT values, WHO generated a scale to classify caries severity. DMFT values between 0.0 - 1.1 were very low; $1.2-2.6$ were low; 
2.7 - 4.4 were moderate; $4.5-6.5$ were high; values exceeding 6.6 were very high [5].

In Hyderabad (HYD), the oral health care systems are in developmental stages. Unfortunately, to date, the dental caries status among the school children population in Hyderabad has very little documentation. Hence, systematic data collection regarding dental caries is vital to evaluate and plan oral health care for the school children. Therefore, the current study was planned to provide the baseline data on prevalence of dental caries among 5-12 years old school going children of rural and urban areas of Hyderabad.

\section{MATERIALS \& METHODS}

The study was started in October 2017 and completed in March 2019. The study population consisted of children aged 5 to 12 years attending the school in Hyderabad (HYD) district. The study sample consisted of 1000 children out of which 575 were boys and 425 were girls. The list of schools was prepared according to the information given by district education officer, HYD. According to the list, schools were divided into four categories, i.e; East, West, North \& South schools of Hyderabad and from each category about 2 schools were selected randomly. A total of 8 schools were selected for the study in which 4 are government and 4 were private schools.

The age groups of 5 to 12 years were divided into Group I - 5-8 yrs. and Group II - 9-12 yrs. to screen the primary, mixed and permanent dentition with caries except the third molar as it is not erupted at this age. Each school principal and class teacher were informed about the study and invited to participate in the study. All children who are enrolled in the study were given a parent introduction letter with an attached consent form. Prior to the main survey, dental examiner performed a calibration and coding exercises for his practical experience in the study methodology. Children with the consent to participate in the survey were examined in their school, in the classrooms using a disposable mouth mirror (Denlite, Welch Allyn Ltd,
Ireland) and blunt ball-ended probe (Hu-Friedy, Dental, Chicago, USA) under day light. All teeth were examined and notated in FDI two-digit nomenclature.

Based on the visual - tactile criteria, caries diagnosis was documented using DMFT/deft index. This index scores for each children were computed for primary and permanent teeth. Data was verified and subjected to statistical analysis (Statistical package for the social sciences (SPSS), Version 10).

\section{RESULTS}

A total of 1000 school children were involved in the study out of which, $481(39.16 \%)$ belong to age group I and $519(23.54 \%)$ belong to age group II. In Group I, 254 (26.78\%) were males and 227 (29.88\%) were females. In Group II $321(73.22 \%)$ were males and $198(70.12 \%)$ were females (Table-1). The number of caries free children among 1000 school children were 281 , indicating the caries prevalence in school children of hyderabad was $75 \%$.

The mean $( \pm S D)$ DMFT values for Group I and II was $0.31 \pm 1.0$ and $1.48 \pm 2.1$ respectively and the mean deft $( \pm S D)$ values for Group I and II was $1.90 \pm 1.91$ and $1.14 \pm 1.36$ respectively.

The prevalence of caries among the groups were highly significant $(\mathrm{P}<0.001)$. Among DMFT/deft scores DT/dt (decayed) values were high when compared to M-missing and F-filling values (Table-2).

Male children exhibited a higher mean $( \pm S D)$ DMFT/deft values $(0.68 \pm 1.45 / 1.29 \pm 1.62)$ when compared to females $(0.66 \pm 1.29 / 1.03 \pm 1.48)$, but it is not statistically significant.

When compared to rural and urban areas of Hyderabad, the children of rural areas are having more caries $(0.75 \pm 1.43)$ when compared to urban areas $(0.60 \pm 1.33)$, which is statistically significant $(\mathrm{P}<0.05)$.

Table-1: The total number of subject

\begin{tabular}{|l|l|l|l|l|l|l|}
\hline Age & \multicolumn{3}{|l|}{ Male } & \multicolumn{2}{l|}{ Female } & \multicolumn{2}{l|}{ Total } \\
\hline & No. & $\%$ & No. & $\%$ & No. & $\%$ \\
\hline Gr.I-5-8 yrs & 254 & 26.78 & 227 & 29.88 & 481 & 39.16 \\
\hline Gr.II-9-12 yrs & 321 & 73.22 & 198 & 70.12 & 519 & 23.54 \\
\hline Total & 575 & 44.12 & 425 & 41.75 & 1000 & 50.01 \\
\hline
\end{tabular}


Table-2: Total DMFT/deft scores in permanent and primary dentition

\begin{tabular}{|l|l|l|l|l|l|}
\hline & & \multicolumn{2}{|c|}{ Total DMFT } & \multicolumn{2}{l|}{ Total deft } \\
\hline & & Mean/SD & P value & Mean/SD & P value \\
\hline \multirow{2}{*}{ Age Groups } & Group I & $0.31 / 1.06$ & \multirow{2}{*}{$0.0000(\mathrm{~S})$} & $1.90 / 1.91$ & \multirow{2}{*}{$0.0000(\mathrm{~S})$} \\
\cline { 2 - 3 } \cline { 2 - 2 } & Group II & $1.48 / 2.12$ & & $1.14 / 1.36$ & \\
\hline \multirow{2}{*}{ Sex } & Male & $0.68 / 1.45$ & $0.8009(\mathrm{NS})$ & $1.29 / 1.62$ & \multirow{2}{*}{$0.0088(\mathrm{NS})$} \\
\cline { 2 - 3 } \cline { 2 - 3 } & Female & $0.66 / 1.29$ & & $1.03 / 1.48$ & \\
\hline Area & Rural & $0.75 / 1.43$ & $0.0818(\mathrm{NS})$ & $1.05 / 1.66$ & \multirow{2}{*}{$0.0079(\mathrm{~S})$} \\
\cline { 2 - 3 } & Urban & $0.60 / 1.33$ & & $1.31 / 1.45$ & \\
& & & & & \\
\end{tabular}

SD: Standard Deviation, NS: Not Significant, S: Significant.

\section{DISCUSSION}

Dental Caries is the most prevalent oral disease worldwide. With the introduction of various significant preventive measures and generalized increased awareness among the masses there has been a changing trend concerning the distribution of dental caries among the indexed ages i.e. 5, 12 and 15 years [6]. The present study selected the age groups of 5-12 yrs based on following criteria:

1. It is likely that at these ages all primary teeth and permanent teeth except third molars will be present.

2. These age groups are considered as the global monitoring ages for international comparisons and monitoring [7].

The DMFT/ deft index using WHO diagnostic criteria to identify dental caries was employed in the present study for following reasons:

1. The majority of the published literature followed WHO criteria in diagnosing dental caries.

2. WHO excludes initial lesions from diagnostic criteria due to concerns over reliability in diagnosis resulting in unreliable data [8].

It was observed that the caries prevalence of group II was higher than group I where as deft of Group I was higher than group II indicating permanent dentition is effected more in 9-12 yrs age group and primary dentition is effected more in 5-8 yrs age group $(\mathrm{p}<0.001)$.

In over all, primary dentition is having high mean deft (1.90) than permanent dentition. This was found to be similar to the results of Jensen et al, 1973 [9] and Manji F, 1984 [10].

The reason for high caries in primary dentition could be due to diet higher in sugars and inability of young child to properly brush their teeth on their own. Besides this, lack of preventive programs in the hyderabad district could be another reason.

Results indicated that male children had higher mean DMFT/deft value than the female children. Similar results were found in studies done by Jain M, 2001 [11] \& Joyson Moses et al., 2011 [12]. The reason may be a marked preference for sons regardless of the socioeconomic status, which leads to longer feeding of sons compared to daughters. Whereas in a study done by Shingare et al., 2012 [13], female children showed higher incidence of dental caries than male children due to frequent snacking habits and fluctuating hormonal levels during puberty by female children.

Children residing in rural areas of HYD had high mean DMFT value (0.75) than children in urban areas $(0.60)$ which is statistically significant $(\mathrm{P}<0.05)$. This indicates that, the children of rural areas exhibited significantly increased risk for dental caries than children of urban areas. Increased dental caries in rural areas might be due to fewer advanced dental service clinics and also due to eating habits and life style differences between two groups [14].

Children from higher socioeconomic backgrounds were generally enrolled in private schools and children from lower socioeconomic backgrounds attended public schools. Hence school type was selected to assess children from different socioeconomic backwards. The study showed that private school children had a lower caries than public school children, consistent with results reported by Pioresan et al., 2011 [15].

\section{CONCLUSION}

The following findings can be concluded from this study:

1. The dental caries prevalence in children of hyderabad was $75 \%$.

2. Age group of $5-8$ years are having high caries prevalence where compared to $9-12$ yrs age group.

3. Male children are at more risk for dental caries than females.

4. Children of rural areas were significantly at more risk for dental caries than children of urban areas.

5. Children from higher socioeconomic status were having less caries than children with low socioeconomic status.

\section{REFERENCES}

1. Prakash H, Sidhu SS, Sundaram KR. Prevalence of Dental Caries among delhi school children. J Ind Dent Assoc. 1999;70:12-14. 
2. Damle SG Patel AR. Caries Prevalence \& treatment needs amongst children of Dharavi, Mumbai. Community Dent Oral Epidemial. 1994;22(1):62-63.

3. Joshi N, Rajesh R, Sunitha M. Prevalence of Dental Caries among school children in Kulasekharam village: acorrelated Prevalence survey. J Indian Soc Pedod Prev Dent. 2005; 23(3):138-40.

4. National Oral health survey \& Fluoride mapping. An epidemiological study of oral health problems \& estimation of Fluoride levels in drinking water. Dental Council of india, New Delhi, 2004;32:6778.

5. Broadbent JM, Thomson WM. For debate: problems with the DMF index pertinent to dental caries data analysis. Community Dent. Oral Epidemiol. 2005;33:400-409.

6. Hansa Kundu, Basavaraj Patti, Ashish singla, Chandrashekhar Jankiran, Swati Jain, Khushboosingh. Dental Caries scenario among 5, $12 \& 15$ year old children in india- A Retrospective Analysis. J Clinical and Diagnostic Research. 2015;9(7):1-5.

7. Aggeryd T. Goals for oral health in the year 2000: Cooperation between WHO, FDI and the national associations. Int. Dent. J. 1983;33:55-59.

8. Klein H, Palmer CE, Knutson JW. Studies on dental caries: Dental status \& concerns of elementary school children. Public Health Rep. 1938;53:751-765.

9. Jensen K, Kizito EK, LangenBaek J \& Nyika TA. Dental caries, Gingivitis \& oral hygiene among school children in Kampala, Uganda. Community Dent. Oral Epidemiol. 1973;1:74-83.

10. Manji F. Gingivitis, Dental fluorosis \& Dental caries in primary school children of Nairobi, Kenya. East Afr Med. J. 1984;61:524-532.

11. Jain M. Save our future mothers. Indian J Prev Soc Med. 2001;32:89-90.

12. Joyson M, Rangeeth BN, Deepa G. Prevalence of Dental caries, socio-economic status \& treatment needs among 5-15yr old school going children of chidanbaran. J Clinical and Diagnostic Research. 2011;5(1):146-151.

13. Shingare P, Jogani V, Serekar S, Patil S, Jha M. Dental caries prevalence among 3 to 14 year old school children, Uran, Rigad District, Maharashtra. J contemp. Dent. 2012;2:11-14.

14. Mohammed Al-Darwish, Walid Ansari EI, Adulbari Benes. Prevalence of dental caries among 12-14 year old children in Qatar. The Saudi Dental Journal. 2014;26:115-125.

15. Piovesan C, Padua MC, Ardenghi TM, Mendes FM, Bonini GC. Can type of school be used as an act indicator of socioeconomic status in dental caries studies. A cross-sectional study. BMC. Med. Res. Methodol. 2011;11:37-41. 